\title{
Christianity and a New Humanism
}

\author{
Historical-Theoretical and Theological Reflections on the Bible, \\ Hegel, and Musil
}

Kurt Appel

\section{Preliminary Remarks}

In the following essay I attempt to lay bare a certain perspective on the human condition, which must precede any approach to the question of humanism. The perspective I seek to develop here combines a highly specific understanding of the SACRED with a distinct conception of time and history. My aim is to unify the understanding of God, man, and time, and to this end I will cite excerpts and ideas from three of the most significant texts in human history - the Bible, Hegel's Phenomenology, and Robert Musil's The Man without Qualities.

This project not only involves the three disciplines that are intertwined with these texts and the necessary dialogue between them but also three temporal eras (linked with specific regions). First, time from its beginning to its end (connected with the cosmos and heaven), second, Europe's history insofar as it extends to the Enlightenment and its distorsions and thus the present day, and finally, Austria or Vienna for the first half of the twentieth century (Freud, Schönberg, Gödel, Schrödinger, Klimt, Wittgenstein, etc.) as, what we will discover to be, a paradigmatic epilogue to history. All three approaches will be woven together through a category which I will refer to as transition. Together with the theme of the body (or a sphere formed by the body'), and the question of time, this will provide the key to a greatly enhanced understanding of God, history, and the human condition.

1 M. Merleau-Ponty captures this sphere wonderfully in his grandiose "Phenomenology of Perception": "It is a nexus of living meanings, not the law for a certain number of covariant terms." See M. Merleau-Ponty, Phenomenology of perception, London 2005, 175. 


\section{First Transition - From World Time to the Feast and Death}

\section{A. The Seventh Day}

The first great story of the Bible, the so-called priestly creation story $(\text { Gen 1:1-2:3 })^{2}$, tells of seven days'work. This cantus firmus of the entire Bible thematizes time in the sense that salvific history is located within time and the understanding of who is God and who is man becomes clear with the correct understanding of time. This is evident in the simple fact that the topic of time frames the entire pericope. Day One as the beginning of time, bears witness to its basic structure:

God called the light "day" and the darkness he called: "night". And there was evening, and there was morning - day one. (Gen 1:5)

Day One as the basic element of time begins with the evening. The structure of the day indicates a sequence that moves from the evening, in other words, a period that leads to death, through the nightly interruption of day as an expression of the sphere of death, and finally to morning as a new beginning, a symbol of the recreation of the earth (this three-part structure is also the background to the resurrection of Jesus on the third day, making it not just a chronological, but also a theological date).

As a result, human beings' path out of a time subject to death towards the (festive) recreation of the earth, which is coupled with a new political and humane dawn, becomes manifest here both as the content of this time and as the cantus firmus of the Bible. The fourth day as the center of the creation story symbolizes the period of festivity determined by sun, moon, and stars, a period that not only structures human life, but also makes it worth living. Finally, the seventh day ends the work of creation and highlights the eschatological dimension of time.

By the seventh day God had finished the work he had been doing; so on the seventh day he rested/celebrated from all his work. Then God blessed the seventh day and made it holy, because on it he rested from/celebrated all the work of creating that he had done. (Gen. 2:2-3)

2 For a detailed interpretation see E. Zenger, Gottes Bogen in den Wolken. Studien zur Komposition und Theologie der priesterschriftlichen Urgeschichte (SBS 112), Stuttgart 1983. Furthermore: G. Borgonovo, L'inno del Creatorale per la bellezza della creazione ( $\mathrm{Gn} 1,1-2,4 a)$, in: G. Borgonovo (ea), Torah e storiografie dell'Antico Testamento, Torino 2012, 393-428. 
The sixth day preceding the seventh contains God's final work of creation, namely the human being as man and woman. In their interrelatedness they are YHWH's image and representation, and their creation completes the earth as the home for all living things. ${ }^{3}$ On the sixth day, then, the world appears as a festively adorned "good" and "completed" cosmos. In this sense, the seventh day is "superfluous". It brings neither new works nor any chronological extension and yet it is this day that concludes the work of creation and that paradoxically - in that it does so again and thus "superfluously" - completes the completed world. Its purpose lies in an open ${ }^{4}$ transcending of the six days' work that prevents time from being a disposable totality that is to be filled by works and is under the control of man, and that time is exhausted in "world time".

The biblical conception of time also highlights the great shortcomings of many creationist and evolutionist understandings of time. These ignore the sphere of the seventh day by objectifying time and using it to construct an uninterrupted chronology, an unbroken sequence observed by God in the former and the scientist in the latter case. Time becomes the chronologically representable object and framework of our knowledge.

However, such a conception fails because the narrator and observer of this representation can never include himself in this picture. Unable to add himself to the equation, the narrator and observer must always leave himself out. Even if we could compose a perfectly causal chronology up to the moment of narration there would again be a distance between this moment and the narrator, a gap that could never be bridged.

In its philosophical dimension the "seventh day" is an addition, a space of opening, a leap and an elusive form of transcendence. To the extent that this day is not representable, it cannot be fully known by one particular discipline (is the relationship between Kant's "causality of freedom" and "causality of nature" not essentially the same as that between the seventh day and the six days' work?) The first six days seem to be representable, the seventh day eludes objectification, and thus creates the space for the subjectification of man and for all living things, which, without this addition, would exist as mere zombies or machines, as the living dead.

3 This idea represents a democratic revolution in the understanding of the human being and its significance can hardly be overstated. It is no longer the ruler who guarantees the order of creation as God's representative on earth, but rather the human being as such in the form of man and woman who is appointed to creatively continue God's creation, with responsibility for the order of society and world.

4 It is crucial that the final formula is missing. Compare Zenger, Gottes Bogen, 100. 
The seventh day is therefore not a chronological appendix of the other six days. The verb shavat (to rest, cease) is sometimes translated as "celebrate" (by Buber for example), which expresses a profound truth because it is the festival in all its exuberance - whose spirit subverts every chronology and every form of feasibility - that brings time in its true sense into play and transforms chronos into free and human time (a feast envisioned and preplanned down to the last detail would be the opposite of a true feast, a mere charade). In the the six days' work, the whole world comes into view both temporally and locationally, but it acquires its meaning through the transition to the feast, when it is opened up to the festival.

Time (or world time) is thus fundamentally more than the accumulation of its moments. It becomes human only at the point where chronos is lifted in favor of the no longer representable feast. Preparations are certainly made for this feast in the time preceding it, often down to the tiniest detail, but it gets its force from an addition not amenable to projection or prediction, in other words a contingent-chance one. Perhaps at this point we might start to ask whether the way in which the "superfluous" (superbundant) chance qua chance expresses itself celebratorily is not in fact a key aspect of the feast. ${ }^{5}$

This addition of the seventh day finds a particularly clear expression in Sunday. In the liturgical understanding of Christianity, it has always been regarded as an "eighth day", which transcends time and reinforces the motif of the seventh day. The sabbath was inserted into a chronological framework as a day of rest, which was a cultural advance on everyday time as an uninterrupted flow but also a contradiction as this addition is not amenable to chronologization. So Sunday, as the eighth day, now signified the "exceeding" of the sabbath, returning it to its original meaning as the day that "crosscuts" all other days, that transcends and overrides them. In this way, Sunday is not simply a day work-free day, but signals the start of the feast, which can extend to every day, but can also be made to disappear at any time, because it is almost invisible and inaccessible in its superfluity. Insofar as the eighth day also coincides with the day one - the day of creation - it expresses another dimension of it, namely, the fact that the world is created in the feast, so the festival itself is not only the goal but also the origin of the world.

This interpretation of the "seventh day" (or the eighth day as its continuation and radicalization) as a messianic overflow and feast day is also important, so

5 The utterly sad thing about our world is that there is no more space allowed for this contingent moment. The ideal consists of complete plannability and describability, in the complete filling of time. Insofar as there are at least two elements in the living being that escape this "filling", namely, birth and death, they must also be brought to a standstill by replacing the living by the machine or by absorbing it into a seamless recycling process. This logic actually requires man's cemeteries to be replaced by compost heaps or district heating plants. 
it seems to me, with regard to the sabbath debate between Jesus and his theological opponents. It was not only a question of interpreting the sabbath more or less liberally because even the Pharisees, Jesus's most frequently mentioned theological adversaries, were open to the need to heal and save on this day. Rather, the core issue is about the messianic claims made by Jesus. The Sabbath is that temporal and festive (but not ascertainable) gate, through which the Messiah enters and in which the world is newly created. Therefore, when Jesus heals on the Sabbath, he claims to regenerate the world through an act of pure creativity as the Messiah and "the finger of God" (in a comparable and striking way this is evident in the multiplication of the loaves, which we must interpret in light of what it means to be radically creative ${ }^{6}$ ).

As a definition of history, the seventh (or eight) day thus designates the transition to "superfluous" messianic time, more festive even than the wedding, which is assigned to the fourth day. But what is being celebrated remains an open question. An examination of key words in the biblical text suggests a connection with Ex. 39:32, $43^{7}$ and thus connects the seventh day with the encounter of God at the sanctuary.

However, the question raised has not yet been adequately answered. While the encounter with God expresses his temporalization in the festival, this does not explain what is being celebrated. An interpretation of the seventh day requires a reading of the next biblical pericope (which in this sense is not to be thought of as a next pericope, but stands together with the first), that is, of Genesis 2:4-3:24, the so-called Yahwistic History of creation and the Fall. ${ }^{8}$

\section{B. The Gown of Grace and the Nakedness of Existence}

The interpretation of the so-called Fall still predominantly takes place in two perspectives, which are opposed to each other: the classical interpretation places an innocent human being in the garden of paradise, from which he falls by the infringement of a divine commandment. The consequences are sin, death, alienation, and the transition from God's eternity into time. In this interpretation, man before original sin is conceptualized virtually as an infant, which is still "beyond good and evil". This makes it difficult to understand how sinlessness could be thought of: as infantility?

6 See part IV: The Price of Prayer.

7 See Zenger, God's Arch, 171.

8 A more detailed exegesis of the pericope is provided by G. Borgonovo, La grammatica dell'esistenza alla luce della storia di Israele (Gn 2,4b-3,24), in: G. Borgonovo (Ea), Torah, 429-466. One of the key insights of Borgonovo's exegesis is the significance of the seven part structure to this section as well, for example, $2.7-15$, where we are presented with a settenarium of perfection. 
The interpretation of the Fall produced by German idealism operates largely in the same premises, but with the opposite consequence. Here the Fall is again associated with the transition from prehistory to history, but it is viewed positively as a departure from the twilight state of human existence. On this reading, history as a journey into time means that human beings take on guilt in order to attain freedom ( felix culpa).

It seems to me that both perspectives fail to do full justice to the subtlety of the text, not least because they try to read the Yahwistic story of sin and paradise independently of the first creation text. Before going into possible connections between the two texts in more detail, I would like to focus on one particular aspect of the story of paradise and the Fall, namely the explicitly mentioned trees: The tree in the middle of the garden of Eden, the tree of life, and the tree of knowledge of good and evil.

Now YHWH God had planted a garden in the east, in Eden; and there he put the man he had formed. YHWH God made all kinds of trees grow out of the ground, trees that were pleasing to the eye and good for food, and the tree of life in the middle of the garden, and the tree of knowledge of good and evil. (Gen. 2:8-9)

This passage tells us about the layout of the garden of paradise, which could be said to be the location of the feast (anticipated in the first pericope), which takes the form of a planting of trees, two of which are explicitly mentioned: first the tree of life in the middle, and second, the tree of knowledge of good and evil. ${ }^{9}$ It is to be emphasized that in the first setting the tree of life is at the center of this festive world, while the tree of knowledge as an additive is not clearly localized (this tree may be situated besides the tree of life but also beyond the rest of the garden). Here a parallel to the seventh day is suggested:This day was not chronologically definable and crossed the temporal horizon of the other days. It was just as well in the center as "outside" of the order of time (or rather, beyond the inside/outside dichotomy) as the tree of knowledge resists location in the garden. Let us consider the second passage in which the trees appear:

YHWH God took man and set him in the Garden of Eden to work and to take care of it. And YHWH commanded the man, saying, "You are free to eat from any tree in the garden; but you must not eat from the tree of knowledge of good and evil, for when you eat it you will certainly die. (Gen 2:15-17)

9 The Septuagint interestingly speaks of a "tree of knowledge of what is good and evil", and gets in this epistemological emphasis probably a subtle point of the Hebrew text. 
At this point man learns that his purpose is the creative planting and tending of this utopian place of paradise, which has an openness in the non-localizable tree of knowledge. It is not said that man should not eat from the tree of Life, which appears to radiate across the entire horizon of the garden. It should be noted, however, that the tree of knowledge is now more strongly centered. This is its first displacement from the "placeless place" to a (negative) place of prohibition. Still, the tree is not localized any further and thus remains apart from man.

The third passage to thematize the trees brings with it another shift:

Now the serpent was more crafty than any of the wild animals YHWH God had made. He said to the woman, "Did God really say, 'You must not eat from any tree in the garden'?" The woman said to the serpent, "We may eat fruit from the trees in the garden, but God did say, 'You must not eat fruit from the tree that is in the middle of the garden, and you must not touch it, or you will die"' (Gen 3:3-4)

What is crucial here is that in this passage, the forbidden tree, the tree of knowledge, has moved center stage in place of the tree of life, and is thus placed at the heart of human desire. In this sense the snake is already the embodiment of desire, that is, the projection of desire, not just an external tempter. Projections also determine what happens next: We are told that the eyes will be opened through the fruit of the tree of knowledge, that the tree is "pleasing" to the human eye and "desirable for gaining wisdom".

In other words, the tree becomes the abode of the "self". The nature of the self-knowledge imparted through its fruit is also described. This is the knowledge of the "nakedness" that now catches the human being's eye. It could be argued that this means that the human being finds himself confronted with an almost inscrutable, all-absorbing emptiness (the "Evil"). The tree of knowledge (as well as the seventh day, when it is interpreted as a wearisome emptiness) transforms into the pure (self)-absence from which man is seeking to protect himself. ${ }^{10}$

Evidently, then, a crucial shift of perspective had taken place even before the eating of the fruit: the tree of knowledge was originally displaced from the human field of view and thus beyond the possibility of direct human projection. It thus had a status between belonging and non-belonging like the sacred, which touches the profane without being part of it. The tree of knowledge, whose "betweenness" makes it the guest - the guest being at the centre of the

Think of the phenomenon of the horror vacui! 
home/the sphere of the "own" without belonging to it" - of the tree of life and of the human horizon, now moves to the centre of desire, triggering an attempt at appropriation.

Up to this point, in its very extraterritoriality (like the seventh day) as something that eludes the human conceptual world, the tree represented a protective layer through which the human being was in a sense reclothed. Man did not have to be ashamed of his nakedness because the self-decentering gap in his field of vision, bestowed by this tree, prevented him from creating an absolute projection for his self. That is to say this projection known as the "dress of

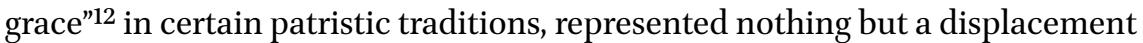
of the human gaze from its total power of disposal over itself and others. The tree of knowledge then is the symbolization of a self-deprivation (a kind of permanent transition between the middle of life and its margins which transcends the self), which is crucial if we are to be opened up to the other.13

In the extent to which the tree now comes into the center and becomes part of man, in other words, at the moment when man begins to transform the open garden into a delimited horizon of his own desire, he begins to locate his self in the sense of a narcissistic projection. The projection of one's own desire (and self-oriented desire), as symbolized by the tree of knowledge placed in the center, then takes the form of the tempting snake before finally, at the moment of absolute assimilation, morphing into the terror of absolute nothingness, the knowledge of one's own nakedness, in other words of the void associated with unmediated presence and loss of detachment (we might compare this to the meaninglessness of pornographic presence). The "opening" eyes no longer experience the original self-withdrawal expressed by the non-integrable tree of knowledge (as the encounter-triggering negation of all projections and assimilations) as a "good" difference between man and God. Through the attempted appropriation of the self-withdrawal expressed through this difference, this experience is instead objectified as "naked nothingness" and perceived as evil.

In contrast to original nakedness, this nudity is no longer that inviting, non-projectable "companion", that "second body", which is never directly visible, which enwraps us and is capable of relationship (we might see this as

11 See H.D. Bahr, Die Sprache des Gastes. Eine Metaethik, Leipzig 1994. Bahr, Die Anwesenheit des Gastes. Entwurf einer Xenosophie, Nordhausen 2012.

12 Cf. Augustine, De civitate Dei, XIV, 14.

13 The Septuagint seems to be aware of the significance of this limitation when it calls the "tree of knowledge of good and evil" a "tree of knowledge of that which is knowable of good and evil." Augustine gives a profound interpretation of this structure when he speaks of the fact that the "good" first became visible as something that had been lost and that the tree bears a reminder of it (De civ. Dei XIV, 17). In this sense, the good would be precisely what is accessible to us only in memory, but not directly. 
an expression of the divine itself), a transcendent companion or body that furnishes the human being with a protective second skin like a dress of light (though as we shall see its protective powers are limited). But this nakedness after the Fall is rather a consequence of an attempt at absolute self-presentation (accompanied by the desire for a presentable God) in the mirror of one's own immeasurable desire.

Just as the feast, which is fully inserted into a chronology of planning, becomes a mere charade, and just as the seventh day, when its particularity becomes objectified, can only function as meaningless time or deathly boredom, this nakedness, which originally clothed the self in its own deprivation as a reference to the divine, now becomes mere absence, an unbearable emptiness. The protective layer of its own unavailability is lost to man in the moment the layer is moved into the human horizon and becomes manageable ("eatable"). Hence the divine measures (distance from the tree of life and from paradise, imposing mortality over man) seem like restitution measures, simulacra of the original protection. ${ }^{14}$ In a sense, the relocation out of paradise repeats the relocation of the tree of knowledge, because only in that relocation the tree of knowledge was allowed to enter into man's horizon.

A similar parallel exists between death and the "dress of grace". After the loss of the dress of light, death is the second clothing of man, that ambivalent mask which protects him from the annihilating emptiness of the totality of his desiring gaze, insofar as we are detached from ourselves and each other in death.

So death masks probably served not to ward off any sort of demons emanating from the dead, in other words to protect the living from the dead, but in fact to protect the dead themselves. Death thus simulates that original boundary of nameability, in which man was enveloped, a limit which when exceeded leads not to God or to a thing in itself, but to absolute nothingness. All further garments and forms of security, with which God gifts the human being, are elaborations and simulacra of this death mask (simulacra of the simulacrum), so that man has no need to be "like God". This also explains the significance of the separation of man from the tree of life. At the moment when man has acquired absolute penetrative power by partaking of the tree of knowledge, death becomes the last tragic safeguard separating the human subject from his own gaze, that is, from total self-objectification as his own double, in which we would face the ultimate horror.

14 It would be necessary to ask whether the expression "the man has become like one of us, knowing good and evil. He must not be allowed to reach out his hand and take also from the tree of life and eat, and live forever." (Gen. 3:22) that God himself knows the danger inherent in this all-controlling gaze. We might also wonder whether the enigmatic plural in the self-designation of God (beyond a pluralist majestatis) suggests a way out of this danger. 
All of this may perhaps suggest an initial attempt to answer the question of what is actually celebrated on the seventh day: it's the encounter with God, which expresses a decentring of the human subject, a decentring that finds its expression temporally in the receiving of a non-instrumentalizable and indisposable time of celebration and locationally in the non-occupyability of the garden of paradise. On the seventh day, through his encounter with God, man celebrates his difference from God and from himself and his world as a projectable entity, a difference physically prefigured in both creation stories by the duality of the human being as man and woman. This is associated with an element of indisposability and contingency that renders the human being vulnerable. In this view the feast of the seventh day could be described as an anti-pharaonic (cf. the disempowerment of sun and moon on the fourth day) feast of contingency and vulnerable creatureliness, or as a feast of transition into the sphere of the unavailable, for which death functions as a tragic form of protection.

So death is at once protection and distortion; it is the replacement of an original difference of man with himself, a difference man wished to overcome. Perhaps the statement made by the snake, "You will not die if you eat from the tree of knowledge" (Gen. 3:4) is not simply a lie, but rather the central challenge of God on the part of man. Will man succeed in overcoming his mortality and thus attaining total power over himself and the other? As a result, man will try in various ways to either overcome death and conquer the tree of life or at least conceal his mortality and vulnerability in a series of new masks.

The first such attempt is genealogy, meaning the attempt to gain immortality through descendants. Cain, as the Bible tells us, is the descendant, the firstborn ("Eve said, 'with the help of YHWH I have brought forth a man"” (Gen. 4:1), while Abel is the superfluous breath of wind, that is, a symbol of mortality and impermanence whose side God will stand on by accepting his sacrifice ${ }^{15}$ In the following, Abel will assume a similar role as the tree of knowledge and the seventh day. Abel is killed, as the Bible portrays, but he finds a replacement ${ }^{16}$ who is named Seth (Gen. 4:25).

Thus, the human line running through Seth, insofar replacement of Abel, will not live for itself, but has the function to represent the victims of the Cainite totalitarian will. Abel will no longer be directly present, but he will "accompany" Seth's line of humanity as a reference point and prevent it from

15 See also K. Butting, Abel steh auf!, in: BiKi 58 (2003), 16-20.

16 See, in particular, the second part, "From the Name of God and the Opening of New Linguistic Areas." 
living for itself, thereby achieving its decisive opening to the other like the seventh day and the tree of knowledge.

I will now temporarily interrupt these biblical retellings and turn to a text that manages to develop and reflect upon the ruptures, projections and transitions alluded to in the first part, namely Hegel's first great work, the Phenomenology of Spirit.

\section{Second Transition - From the Contingency of Existence to the Body of God}

\section{A. The World as Mirror of the Self and its Shattering-Consciousness, Self-Consciousness, Reason and Spirit in Hegel's Phenomenology of Spirit}

Hegel's Phenomenology of Spirit (hereafter Phenomenology) ${ }^{17}$ is probably the last great philosophy-of-history project of our era. It is a text in which projections, masks and transitions - of the kind indicated in the first part of this article - are of paramount significance. If we consider this work's point of departure, we find that it picks up where the story of the paradise ends and other texts of fundamental importance to Europe (the story of Abraham, the Odyssey, the Aeneid) have all begun, namely at the way in to the unknown.

In the first instance the path of the Phenomenology is one of despair, and as we shall see it does not necessarily culminate in a "happy ending". Hegel's point of departure is the situation of the (modern) self, which attempts to locate itself and its reflection in the world it encounters in order to gain power over itself (and others). The fundamental theme of Hegel's early writings, or Jugendschriften, that the self expresses itself in its relations with others and its encounters in the world - and thus the self is fundamentally intersubjective and is always situated "between" the individual and the general self ${ }^{18}$ - plays a particularly prominent role in the Phenomenology.

The self sees the world as a mirror in which it is to discover itself. Hegel identifies various stages on this journey of discovery, all of which share the same fate: the self is ultimately unable to find itself in them. The self experiences itself as

17 Quotes in what follows from G.W.F. Hegel, The Phenomenology of Spirit. Translated and edited by Terry Pinkard, Cambridge 2018.

18 In Hegel's work, the self is to be regarded neither in abstractly individual nor abstractly collective terms, but always as a transition between the individual and the general. Language is a good example of this as something prior to the individual that is also shaped by him. 
detached, as negative in relation to the world it encounters. At the same time, however, the world of the self is not simply a static object; it changes shape every time the self approaches it in a new way.

One might say that in every approach of the self to the world, the latter expresses itself as the new experience of the loss of the former. "Self" and "world" (and "language") are correlative entities. The world is linguistically and mentally mediated as a world-encounter, the result of the perpetual withdrawal of the self, which cannot find itself in the world, while language echoes this experience of withdrawal. Within this experience the world and the self have a radically temporal structure. Thus "time" is not a collection of definable moments within a chronological series, nor a substratum of any kind of event-particles upon which it is based. Time is the detachment that the self experiences in its world-encounter in which it is trying to situate itself within the world.

Therefore, every view of the world is a temporal form of detachment. Fundamentally speaking: the self as that which remains location-less with respect to its world and experiences itself as separate, the world as a projection screen for the configurations of various experiences of loss, time as the process of this detachment, negativity as the perpetual transition of the self and of its constructions of the world and death as the most radical experience of self-detachment are interpenetrating spheres which in turn, as it will be shown later, lead to the idea of God.

At this point it should be emphasized once again that the self is neither an object nor a worldless subject, but rather a linguistically and intellectually ${ }^{19}$ (culturally-intersubjectively) mediated encounter with the world (while the world is the linguistically and intellectually mediated encounter with the self). As indicated above, all of these encounters end in radical failure because the self finds no place in this world to which it might hold onto.

Let us focus on some selected stages of this process of (not) finding: The self attempts to locate itself in the unmediated singularity of sensuous-certainty, which, however, is subject to a process of constant disappearance. Then comes the attempt to locate itself (self-reflection) in the object-world of perception, which fails due to the dialectic of the unity of the object and the plurality of its qualities. Next, the attempt is made to locate itself in the law-based world of understanding in whose fixed and constant laws the law of life cannot be

19 Here, it must at least be pointed out that the phenomenon of language is not limited to the articulated language or sign language of the deaf, but occurs where beings give each other meaning. It should also be pointed out that the "spiritual" is not to be understood as a sum of subject relations. Rather, in Hegel the (general) mind and (singular) subject are in an interaction which transcends every cause-effect relationship. For this reason, intersubjectivity is to be thought of only in terms of the dialectic of the spirit and the subject. 
represented in all its movement. ${ }^{20}$ The self also attempts to locate itself in the desire of the living being, which can never be entirely satisfied because the ultimate desire is directed not towards a finite object but towards "aliveness" itself in all its detachment.

The next stage is locating the self in work as the desire that is "inhibited" by the object. However, the self is unable to find itself in the products of work. This is followed by the self then trying to locate itself by retreating into stoic detachment from the world, through which the self finds itself in an entirely abstract-relationless form, before attempting to locate itself in the skeptical negation of what it encounters. A particularly significant passage is the self's attempt to locate itself in the melancholic desire of unity with the elusive infinite unchangeable (as is especially manifest in today's pop music as a replacement for traditional mysticism, which marks a constant longing for unity with an unreachable vanishing point). The self then "earths" the alterity of this realm of the unchangeable infinite and searches for itself in the unchangeable physical, chemical, and biological structures of being.

This entire searching process ends with one of the Phenomenology's key propositions, which has modern-day biologistic parallels (in light of the identification of the self with gene and protein sequences or neuronal processes): "The self is an object thing". ${ }^{21}$ This proposition is important. On one level it indicates a total absurdity (a so-called "infinite judgment" in which the sphere of subject and predicate falls apart), inasmuch as the spirit cannot find itself in a materially conceptualized entity (the neuronal wave of the brain, for example, will refer to the colour "red" only when a linguistic act of translation is added by the "self"). Likewise, however, the proposition also holds together the "harshest" contradiction within such an "is" statement. This reflects the fact that the "self" becomes concrete only in the radical transition between "spirit" and "matter". In other words, the realm of spirit finds expression in the fully contingent material realm and conversely, the purely material world, insofar as it is abstracted from all its definite forms, is reflection respectively spirit.

20 From Hegel's point of view, life is not only the consequence, but also the cause of the anorganic law-world (and self-consciousness is the cause of both), since the simple difference of the law as a difference (and thus in its true meaning) is the self-distinction of life. This self-distinction, as difference from itself, signifies, in turn, self-consciousness, which, as a self, differs from its world and, as a difference, refers to it. This means a radical difference to today's evolutionary theories, in which self-consciousness is viewed only as an effect of life and life as an effect of inanimate nature. See also K. Appel, Zeit und Gott. Mythos und Logos der Zeit im Anschluss an Hegel und Schelling, Paderborn 2008, 264-269.

21 Specifically, the theorem is: "... and what in truth the foregoing has been saying may be expressed in this way: The being of spirit is a bone." (cf. Hegel, PhdG 201, par. 343). 
Hegel's odyssey does not end here. The self, which does not experience any recognition as a subject in its object, now tries to locate itself in practical endeavours, for instance, in eroticism or virtue, through which it believes it can force the course of the world to run according with its will. One of the most interesting attempts at self-location occurs in the spiritual kingdom of animal. Its world is characterized by a self which no longer places itself in certain modes of dealing with the world and forms of being, but instead defines itself by its absolute flexibility. It is a self that concretes the difference inherent in self-consciousness through its ability to withdraw itself from any given determined world configuration and replace it with a new, opportune one. It finds its identity in this adaptation and ultimately in its "work", from which it has the ability to remain apart. This results in a world of entirely opportunistic adaptability with the consequence that the world loses all substantial content inasmuch as this content becomes a mere representation of the self, which is constantly distancing itself, a self that thus renders itself invulnerable.

This total "relativization" and "liquefaction" of what is encountered, as a mirror of the intangible self, is characteristic of the capitalist money economy, in which nothing has any intrinsic value and everything is subject to a constant re-evaluation (in this respect, every criticism of relativism as an expression of this way of dealing with the world must be accompanied by a critique of capitalism!). This is expressed figuratively in the city of Los Angeles, as a synonym of the modern city, which is pure periphery without a center, pure distance and non-relatedness. In order to somehow still represent itself in this system, the self assumes an arbitrarily changeable brand identity, whose only characteristic is its "non-content" and its pure formality as a brand. At the same time, it is a characteristic feature of this stage that everyone declares his or her own work or replaceable brand as if it were universally valid.

This abstract validity can no longer be filled with content, but it asserts its binding force on everyone, and in its formality it becomes a universal standard for all selves.

One example of this in recent times is the debate on a defining or guiding culture (Leitkultur), which is not content-able (no one knows what this culture ought to be). Its only purpose is to subject people to complete abstract-formal labels and demands (which Hegel has pointed out in the law-testing reason), that revolve solely around the exclusion of the other as the content by which the self gives itself identity.

The next stage in which the self strives to locate itself, is what Hegel calls "spirit."

Here the self appears to find itself in a sphere of a universal whose content is never entirely clear - a sphere that, as an expression of the universal 
self, transcends any definition, in other words any characteristic (just as the individual "self" cannot ultimately be located in any kind of qualities). The singularity of the self and the universality of the ethical community, which is the setting the self finds itself in spirit, seem to completely coincide. According to Hegel, this community of the self and the universal is based on the genealogical family on the one hand, and on the other hand on the polis, both of which derive their self-understanding from a a shared (biological) origin (genealogy) of the subjects.

For Hegel, neither form means the arrival of the self to its long-sought identity, but rather the forms of death in which the self can only find itself as dead. In other words, both the polis-state as well as the genealogically oriented family as the basis of a community are forms of the recognition of the dead, not of the living - hence the supreme importance of war (polis) and burial of the dead (family) in these two forms of community. Both fail to do full justice to the living because the living self is distinguished by a contradiction, by an ultimate non-relatedness, which can not find any corresponding expression in these genealogically structured forms of dealing with the world. Therefore the self can not be recognized in its liveliness.

However, as the self "suffers" this non-reference, the dissolution of its embeddings as its truth, in the structures of the (biological) family and the polis, it finds itself only as an absolutely unrelated, isolated "point", in complete discontinuity with the world and every relationship to it.

Today, many "pre-modern" cultures seem to suffer these experiences insofar as they understand themselves as genealogical and draw their selfunderstanding from this "natural" community but are undermined by the individuality of the modern self and its ability to distance itself from anything and everything. The only way they can defend themselves is by demonstrating their ethical substance - whose characteristics are in fact entirely resistant to identification, since they are prior to all predication - with various abstract themes (headscarf, veal sausages, etc.) ${ }^{22}$ that they then defend as their own unique identity. This triggers a regression to the virtual brand logic addressed earlier, only with the difference that these cultures cannot distance themselves from these themes whenever they like.

Thrown back on itself, the self's next attempts to locate itself consists in its own completely abstract and contentless claim of validity. The first form of this is property, which, as indicated above, is based on an act of exclusion

22 There seems to be in fact a complete arbitrariness of such themes, which are presumably derived from traditions, but without having a living relationship with the culture that supports these traditions. 
and is secured by the law (specifically, property law). In this way, however, the self experiences more and more its opposition to others and to the world, an antithesis, which it finally creates within itself in the second form of the claim to validity, namely in the cultural formation. The hallmark of cultural formation is the inherently contradictory or alienated world which the self experiences through an impenetrable subject-object opposition, which has become such a prominent feature of our own thinking.

On the one hand, this dichotomy is radicalized to the extent of a completely transcendent deistic God detached from the world, together with a worldindependent (Cartesian) subject, and on the other the subjectless and godless object-world of our present day. The self is set against the world as "negativity", that is, as the nothingness of the object-world, and in this way replaces it with a virtual, thought-based world. Hence, the self finds itself reflected in its own thought process, in its intellectuality.

Hegel calls this state "insight". Here we find the second fundamental theorem of the Phenomenology - "the object is self", which must be read in addition to the aforementioned notion that "the self is an object", in order to understand self (subject, spirit) and object (substance, matter) as pure transition into one another, as we shall see. In any case, in this stage, the entire world is taken back into the conception of the self and loses all intrinsic value and "aura":

First, the world is viewed from the perspective of its utility for the self, and finally morphs into a pure projection screen for the self's semantic emptiness, one which has destroyed all reality. The culmination of this corrosion of the world is "absolute freedom and terror". According to Hegel, the European project ends at this stage, which is why the Phenomenology marks an end to all philosophies and theologies of history (which is also how Hegel saw his book): the world as an autonomous entity has retreated fully into the projection of unrelated self-emptiness, which we have already come across in the Fall, a selfemptiness that in the Hegelian version reflects its unrelatedness as absolute nothingness. One could again use an image for this figure - the perpetuum mobile, the fully self-contained machine that expresses the secularized metaphysical God, a machine in which nothing can penetrate from the outside and that is completely intangible in the truest sense of the word.

At this stage, alienation is taken to an extreme and what remains is death as predicate-less absolute, as an absolute nothing (nihil negativum) into which everything returns. It is important to note that at this point the death presented here has nothing in common with human death (nor with animal death), which as seen at the end of the story of paradise, signifies withdrawal as a mask that protects against absolute emptiness of the human will to totality. This death, on the other hand, is the pure, meaningless emptiness, freed 
from every aura. At most this emptiness clings to our finger in the form of a diamond ring as the last echo of the life burned in the crematoria or is manifest in the form of the preserved corpses that give us a bit of a thrill in exhibitions. Politically this stage corresponds, for example, to the absolute nihilism of National Socialism. ${ }^{23}$ And it differs in this pure nullity from fascisms whose content derives from the virtual return into family-genealogical structures of an ethos that has become fictitious in the post-Enlightenment era.

This form of nothingness, entirely devoid of meaning, not only destroys all content, but also its history (absolute freedom, which as negative freedom is no longer related to any object, also detaches itself from all historical-genetic ties). This means that Europe can no longer fall back on the (immediate) heritage of a Christian-Jewish or antiquity-based character but is in the first instance the product of the terror inherent in the obliteration of all content. Alongside the terror manifested in the French Revolution and again on a far more massive scale in National Socialism, there is the second "form" of this absolute nothingness, namely virtualization as the expression of pure reflection, which no longer knows any "outside", in other words any reality. It seems fair to say that the European spirit has found itself in virtual nothingness. We encounter this phenomenon in academic discourse, where topics discussed amount to "nothing" (substantial); in the economy, in which human beings are merely floating around as a mere abstract phantasm within a virtual array of figurations (what are the young unemployed other than number-ghosts, superfluous, virtual); in the transformation of the earth's natural resources into fuel ("biofuel"); and in anthropological discourse, where human beings wander around as strange, heteronomous zombies (the jubilation of various journals every time they "discover" that the human being is a mere function of neuronal or physical mechanism or another is almost sinister).

This virtual world manifests itself through the total interchangeability of temporal trajectories and the arbitrary repeatability of temporal moments (for example, when the video recording replaces the event, as in many modern weddings). This obliteration of any temporal trajectory leaves no place for the new, because in this machine every place has become superfluous as a result of its random interchangeability. Young people, as those who are "not yet" and "future", are thus completely deprived of their place and remain, at best, as a virtual and ghostly ideal of a society which has become timeless.

23 National socialism, in its peculiarity and viciousness, can not be deduced simply from the course of development outlined here. It is, however, also to be understood as a phenomenon of a radically nihilistic "possibility", as it has developed in modern times. 
The final blow wielded by this machinery is to replace life with the cybernetic control circuit. In this manner the tragic, but at least protective, mask of human death falls away, to be replaced not by life, but the pure mirror of virtual nothingness. The question remains as to whether this turn of events brings to an end the European project, or perhaps the human project itself.

Hegel, however, adds an epilogue to this "nothingness", namely (Kantian) "morality" and the "conscience". According to Hegel, "morality", as contentless abstraction and alterable imperative, is inhibited terror (just as work is inhibited desire). But it also has the tremendous attribute of having found a form of universality - everyone is equally subjected to moral law - that does not need to be defined as a genealogical or utilitarian project (as, for example, in the nepotism so prevalent in many parts of the world, which is a travesty of the genealogical-familial community).

However, according to Hegel the terroristic element of this morality consists in the fact that the contingency of nature cannot be "freed"; it remains a projection of the self, which finds itself in the validity claim of the abstract moral judgement. As the final stage in the development of spirit, conscience is addressed by Hegel as an internalized moral judgment, that is, internalized terror.

According to Hegel, at the end of the chapter on conscience, the selfrighteous judgment "collapses", because the self has now found itself as a result of being thrown into a (not fully derivable) further epistemic level; it learns that the secure site of its judgement, from which it has condemned the (contingent) other, was a projection. That is, despite all its impregnability and intangibility, its location was merely virtual. The self "sees" that that which it condemned in the other, namely its finitude and contingency, is in reality the withdrawn, non-controllable place of its own self, or, as Hegel puts it in the Science of Logic, at the transition from essence to conceptual logic, expresses the fact that "being-in-and-for-itself" is "positedness"24.

Through this insight, the contingency of the other is forgiven and the self begins to give up its validity claim. This happens precisely at the moment when it leaves behind its own virtual and secure place of judgement, to which it had withdrawn. From this vantage point, we can define the nature of forgiveness. It is not the activity of the self vis-à-vis another (I forgive you), in which the self occupies an absolute location (and finds itself again in self-righteousness). Forgiveness arises from the insight that the contingent place of the other is

24 G.W.F. Hegel, The Science of Logic, translated and edited by George di Giovanni, Cambridge / New York 2010, 516. 
also my contingent place and that what the self means to forgive has already been forgiven.

In other words, through an act of recognition, by "becoming other to itself", the self does something which, speculatively speaking, has already occurred. Crucially, through this deplacement out of its fictitious location, out of its judgment, which was the reflection of its own validity claim, the self actually loses itself and thus also loses the world as a projection screen. Through this experience of "becoming other to itself" the self is no longer able to project itself into the other and it must therefore abandon the attempt to find itself in the world.

So according to Hegel, the pure virtuality characteristic of our tendency to distance ourselves from everything entails the possibility of a different perception, one that does not regard the world as a mirror of itself. But the question remains, how this step of relocation should be understood. If it is to be deduced theoretically, it would be another self-projection and not due to a relocationary transition. In this respect, we cannot simply identify "causes". However, according to Hegel, there is a deeper way of looking at this transition.

\section{B. Religion as Loss of the Self-on the Significance of Religion in Hegel's Phenomenology of Spirit}

In Hegel's work religion is thought to be the loss of the self, insofar as the self seeks to find its reflection in its world. This view is the exact opposite of Feuerbach's. For Feuerbach, religion was a human projection. However, in Hegel's work all religious forms become metaphors of a loss of projections and thus of the self-conception of the self. Religion's way of configuring things are necessary because they ensure that the self still has some way of expressing the gap it finds between itself and any form of objectivity (projection).

The first way - reminiscent of Kant's remarks on the sublime ${ }^{25}$ - in which the self's relocation and loss of self is given religious form, is the experience of the emergence of a luminous essence (Lichtwesen). The light symbolizes the pure movement, the pure transition, as which the self experiences itself when it ceases to maintain itself. The self will subsequently manifest its downfall as a representable entity (what Hegel calls negativity) in ever more radical form.

When the numinous is portrayed metaphorically as God in animal form it is the disconcerting character of the creature that represents the self's

25 Kant's analysis of the sublime highlights the fact that through the experience of the ascent of the forces of nature the self is irrevocably cut off from the possibility of peacefully inhabiting the natural world. The sense of the sublime then sets in the moment the self internalizes this loss of belonging to nature and begins to transcend natural phenomena through its reason. The form of human reason is thus rooted in human reality of not belonging, which is experienced in the forces of nature in an eerily beautiful way. 
detachment from itself (its relocation out of itself), and it is this estranging character that makes such an image a worthy "bearer of God". In more abstract symbolism the self encounters its own strangeness in the edges of the pyramid, which symbolically express the self's boundaries and its finitude as marked by death. In other words, the edges of the pyramid represent the barriers that stand in the self's way within its self-conception.

The pyramid is also constructed to conceal death. Hence it is the enigma of death through which the self suffers its radical self-detachment and which it affirms in a further transformation as the impenetrability of the sign, as in the hieroglyph. In subsequent religious forms the element of the negative and the contingent, or death as absolute separation of the self from all forms of self-projection, move to the fore. We might say that the metaphor of death represents the self's passage or transition to "becoming other to itself" as the end of all projection.

The gods as expressed in statues should not be understood as unmediated forms of a general self in the sense of idolatry. Instead these representations "freeze" the moment immediately before the onset of the numinous, they are thus the ossified run-up (like the terror of God) that occurs before the event. H.D. Bahr remarks that this is the moment before the possible onset of the gods' laughter, this laughter being the bearer of an alienating meaning that humans are unable to cope with. ${ }^{26}$

So rather than depicting the self, they depict its alienation. Another distinctive location within the framework of religious figurations is language or song, as expressed in the hymnos. As Hegel remarks in his System of Ethical Life, ${ }^{27}$ language maintains the power of the negative, that which withdraws, and is in a sense the creature's scanned death-cry. So if religion represents the self's transition into its no longer projectable other - literally, in as much as religion seeks to cling to this very moment of transition that it undergoes as it breaks with itself (that is, with its projections) - it experiences another expression of this transitionality in language.

Language not only stands at the junction of organic sound and meaning, but is on a deeper level itself an expression of the rupture of the human self. In language the self does not depict a nonlinguistic reality, that is, language is not the symbolon of this reality. Rather, language symbolizes the rupture that self and reality undergo at each other's hands. The human being is never in

26 See H.D. Bahr, Sätze ins Nichts. Versuch über den Schrecken, Tübingen 1985, 327.

27 See Hegel, System of Ethical Life and First Philosophy of Spirit, Albany 1988. See also G. Agamben, Language and Death, Minneapolis 1991. 
reality in any unmediated sense, nor is it ever immediately present with its self. Instead the human being is internally fractured (it is one with neither world nor itself) and the speech sound manifests the self's detachment from any unmediated unity with the world or itself. This means that language, whether it takes the form of articulated words or the sounds of an instrument as simulacrum of the voice (or the articulated movement of sign language), is a superb medium for representing the rupture that the self undergoes as it is detached from its own images, a rupture that is, so to speak, absolutized through death.

Another form through which the religious sphere is symbolized is corporeality as expressed in the movement, for example, of the game (it is the Olympic Games that Hegel initially has in mind). In playful movement, the body becomes a reference to a second habitual body, and one could view the mastery in dance and of the body as a mastery of the transition between the two bodies, the "real" and the "referenced" (the deepest motive for medieval representations of the dance of death may lie in the intuition that the first body consists of eventually being seized by the second body, that is, to make the final transition!).

Before turning to Hegel's interpretation of Christianity I would like to conclude this selection of religious images with two forms, namely tragedy and the comedic consciousness. The most striking feature of the former is the necessity of fate, whose mask conceals death in all its inexorability. Death swallows up gods and human beings and thus emerges as the nothingness of all previous mask-like symbolizations. It thus expresses the truth of the ethos itself (as manifest in the ethical community and family). Above all, however, the self now experiences its complete contingency and its rupture with the world and with itself as it faces the final mask, the death mask, which reflects back no positive self-understanding.

The question that now arises is whether there is still "something" behind this mask. And it is at precisely this point that the comedy begins: the masks fall away as all previous forms and even death is laughed out of existence, (so perhaps Nietzsche is the great comedian of our times). What remains is the naked $^{28}$ self. In contrast to the self-related insight, which in Hegel's interpretation places itself behind its intellectualist validity claim, the naked self has obliterated every mask and (self-)projection protecting it. Because it has shed,

28 While in the case of the fall nakedness reflects the emptiness of the totalitarian gaze and the self-projection that corresponds to it, the nakedness of the comedic self signifies the end of all (self-)projections and thus goes hand-in-hand with a radical knowledge of the contingency and vulnerability of Dasein. Shame, meanwhile, begins with the knowledge of (self-)projections - which separate the self from its own contingency. In this sense we might say that comedy is shameless because it operates at the end of all projections. 
in other words worked through, every mask, the comedic consciousness can say of itself: "The self is the absolute essence". ${ }^{29}$ This detached and naked self is marked by total contingency and singularity and one might ask whether it is not in fact laughter that simulates ${ }^{30}$ an original crack in every mask-like reality.

In any case, an element of contingency seems to be in the offing in this comedic laughter, an element capable, without warning, of taking off the masks of our existence, perhaps even those that make up present day virtual reality. So does God laugh? But why, we might ask, is the Christian God not depicted laughing? Why do we never hear that Jesus laughed (however convinced we may be that this "glutton" and "drunkard" was a source of amusement)?

In the story of the Fall, death cloaked the unfathomable nothingness that concealed the infinite desire for the (re-)presentability of God, while this nothingness in turn obliterated the original clothes of grace, that is, the decentering of one's own power of disposal. In its anarchical attitude towards all projections, laughter now signifies such decentering. But - at least in Hegel's interpretation of the comedy - laughter remains ambivalent, since there is no way to determine whether it offers the self an ultimate refuge and, so to speak, replaces death as a form of clothing, or whether it ultimately has the potential to jeopardize itself by making itself tangible to the other. In this sense, according to Hegel, the self (or all its projections and objectifications) must be sacrificed in a more radical way, namely on the cross, which emerges as necessary for salvation.

Laughter, with its an-archic significance, becomes the springboard for a re-locationary step to a place of radical exposure and tangibility. In Hegel's work, unhappy consciousness, as the "birthplace of the absolute", referred to the attempt - which we encounter through the Fall - to unite the finite human being with the immutable, in other words with God. The unhappiness resulted from the fact that this attempt failed because God remained, so to speak, transcendent of human desire and the union was only ever with one's own desire. Through revealed religion, in other words through the revelation of the cross of Christ, this union now paradoxically occurs through a contingency that is radically exposed to the temporal world.

The pain of the self is no longer the pain of unfulfilled longing but stems from the vulnerability, openness and exposure of one's own existence, in which God becomes present. It is crucially important that the event of the cross is a

29 Hegel, Phenomenology of Spirit, 430, par. 748.

30 Perhaps the canned laughter of present-day sitcoms, as a medium of the virtuality described earlier, serves to simulate the genuine occurrence of anarchical laughter to the point where this laughter is no longer audible. 
singular, absolute event. This is because there is no valid (reflexive) image of it that might serve as a reference point for any kind of repetition that would allow us to tone down the contingent element and bring it under our control. ${ }^{31} \mathrm{It}$ goes so far that the singularity of immediate sensibility and objectivity, that is, body, comes to the fore on the cross as paradoxically the (reflective) language itself is overridden in this place, and thus this event is described as an absolute one, detached from all dispositions, attributions, masks, and garments. ${ }^{32}$

No symbolization, then, can do justice to the absoluteness of this event of the most radical externalization. The subject is deprived of the option of constructing in the other a new projection screen to save itself from this externalization, to once again elude the contingency of being, to evade contact with the other. What vanishes in this instance is an objectifiable God of any kind into which the self might project itself in order to distance itself from its own corpus of tangibility.

Jesus thus is neither an unmediated manifestation of the transcendent God in a modalistic sense, nor the second entity in a heaven of three gods, as tritheism would suggest. Instead he points the way to a relocation out of oneself, a shift that indicates not an external "other" (the world-transcending God) as a mirror of one's own distancing from the other, but to a sphere of absolute tangibility and vulnerability that becomes the only "abode" of God, as the skin of the absolute, so to speak. ${ }^{33}$ This observation brings us back to the story of the Fall and endows the tree of life with a deeper significance. It is the place of absolute tangibility, vulnerability and exposure (in this sense, the old iconography was brilliantly intuitive in depicting the tree as a cross) in the middle of pure, affective communication with the rest of the world. ${ }^{34}$ The tree of life is the bare body, the divine garment of a "second" skin that clothed the human being "before" the Fall.

Paradoxically, the "death of God" also involves a re-evaluation of death, the "death of death" in a sense. Death was conceptualized either as the annihilation

31 In this sense Kant is right to state that all doctrinal theodicies are doomed to fail.

32 Hegel makes the remarkable statement that religion still dresses reality in the garment of our representational thought (Phenomenology, 392, par. 678). Only the cross-event would constitute a final radical divestment, though the churches rush to create a distance from this by placing it in a past or future.

33 The cross of Jesus, therefore, is the affective transition from the actual and the habitual body, insofar as Jesus' body is entirely the reference of God. For a thought of the body as the transition of these two spheres, see also the statements of M. Merleau-Ponty, Phenomenology of Perception, 107.

34 On the affectivity of God, see P. Sequeri, “Nur einer ist der Gute' (Mt 19,17). Theologie der Affektion als Umkehr der Ontologie", in: E. Arens, Ästhetik trifft Theologie (QD 246), Freiburg 2012, 46-72. 
of the self (as expressed in the Phenomenology in paradigmatic form in the chapter "absolute freedom and terror") as in our culture, in which a hopeless nothingness that destroys all meaning (nihil negativum) takes the place of the deceased $^{35}$ (where the deceased becomes "nothing"), or in the more "favorable" case, as an ambivalent mask intended to limit human beings' infinite desire (from a divine perspective). On the cross death no longer means the absence of "something", but both the absence of all images and projections (of selfconcepts and concepts of the other) and the ultimate sealing of this absence.

The ancient gods and religious forms as death-figurations disappear in this absence as do all mundane attempts at self-locating. As a result, Europe stands in the field of tension between two figures of dis-apparition, namely the deadly terror of one's own self-projection and the life-giving cross which means the absolute openness to otherness.

In John 20.11-18 Mary experiences a "reversal" at the grave, at the place of emptiness of all images. She turns away from the horror of the empty tomb that she has expressed to the two messengers of God ("They have taken away my Lord"), a horror into which the world has retreated and that makes it impossible to sustain any imagery. Instead she embraces her determination, conveyed to the "gardener" (does the impossibility of recognizing Jesus in the form of the gardener not indicate this loss of the image?), to retrieve her kyrios from the place of mere absence ("tell me where you have put him, and I will get him"), in other words she is willing to descend into hell, or make the journey into the void. She receives her name spoken by a voice, whereby she recognizes her kyrios, in a second turn, in which the final certainty, namely death as absolutely different non-place, disappears. Jesus' tangibility ("Do not hold on to me") requires postponement, inasmuch as the sphere of the second body must first develop also as a sphere of absolute tangibility.

According to Hegel, the lack of revealed religion, that is, of historical Christianity, consists in the fact that it places the transition of the cross as a paradigmatic transition between the body and the sphere of its absolute tangibility into a past or future event, and thus, once again, strives to shield itself from contingency which is devalued as evil and from the associated vulnerability. In the latter case the liturgical event, which celebrates this transition, is not taken seriously.

\section{Absolute Knowledge and the Body of God}

At the end of Hegel's Phenomenology, in the chapter on absolute knowledge emerges as a key category that of transition. In theological terms it is here that the Holy Spirit manifests itself. Even a thinker such as Maurice Merleau-Ponty,

34 Cf. H.D. Bahr, Den Tod Denken, München 2002. 
who no one would suspect of practising theology, emphasizes the importance of the category of transition - beyond its reduction to a mere shift of location - when he highlights that we "must conceive a world that is not made up of only things, but also has pure transitions." ${ }^{36}$ In Hegels Phenomenology the transition is found in the beginning of Religion itself, inasmuch as its forms symbolized the transition as re-locationary steps by the self out from its projections (that is out of itself).

The most radical point in which the transition occurs can be seen and witnessed as the divine event in itself, on the cross of Jesus. In this event HIS crucified body is seen as an absolute reference to a zone of pure tangibility, one in which the transition as such is opened up between Christ and the Father, contingency and the absolute, man and God, the singular and the universal, matter (thing) and spirit (self), the physical body and the second body that Mary beheld and that was prefigured in the Olympic Games. It is crucial here that in this transitionality every causal trajectory is ruptured and the act of beginning is simultaneously the beginning of another: to touch means to be touched and to give yourself to touching, to recognize means to be recognized and to give yourself to recognizing, speaking is to be spoken and to give yourself to language, telling is to be told and to give yourself to telling, to temporalize is to be temporalized and to give yourself as a temporal form, and so on (it must be added here that both self and time find their essence in transition). ${ }^{37}$

It is particularly important to address the transition between the absolute and the contingent: As demonstrated in revealed religion, the absolute has divested itself completely, it has relinquished in what is given as a separate sphere, and showed up in the sensory tangibility of the contingent self. The transition, which is addressed in absolute knowledge, is that of a self which previously wanted to locate itself in the stages of its projections, or tried to cope with its loss of self, still employing forms or masks, into the total exposure that serves as a "second skin" or second body, which is the body and the tangibility of the absolute itself. Concretely, this has the vexing consequence that God reveals himself in the randomness of a tangible, that is, suffering exposure and existence.

To put it another way: who the human being is in the deepest sense is particularly manifest when he is affected by entirely contingent events. This means that the world and our lives are not, as normally regarded, a reserve of possibilities, most of which are not realized and ever fewer of which remain as life

$36 \quad$ M. Merleau-Ponty, Phenomenology, 320.

37 In Hegel's work time is the unity of subject and object, namely the Concept in its reality (der daseiende Begriff), while Merleau-Ponty states that we must "understand time as the subject, and the subject as time". See M. Merleau-Ponty, Perception, 490. 
proceeds, so we can only hope that God in paradise enables all those things that were denied during our lives. ${ }^{38}$ Instead they manifest themselves in contingent and in completely unpredictable instances in which we are touched, wherein the absolute itself strives to be with us, to the point that we either accept it, or shield ourselves against it. When Hegel speaks of a reason of history, his point is not to turn history into an abstract necessity. What is at issue here is the paradoxical reason of the contingent moment, which we cannot cope with or integrate into our own desire, but whose randomness and exposure are the wellspring of spiritual events. I have no wish to deny that, as the Bible knows, these encounters (with God) can be profoundly hurtful and even life-threatening (see for example Ex. 4:24), such that they are inscribed deeply and for ever in our existence as scars and fissures and there is no ultimate certainty that they will not shatter us. But it must be understood that this is not a matter of any ultimate uncertainty either, since general-theoretical statements no longer work at this point and insight passes over into practice and knowledge into hope.

One more element is to be underlined in this final part. I have pointed out that body of pure tangibility, the tree of life into which time is inscribed, not least as the scars of our existence. From the Christian standpoint, this body or the scripture engraved into it, has a particular shape, namely that of a text, which preserves the memory of who are touched or injured, called the Bible. ${ }^{39}$ The Bible is skin/body become word and signifies the transition between flesh and word.

(Post-)Apocalyptic Epilogue: Musil's “Moonbeams by Sunlight"

\section{A. The Forms of Time and their Transition to Scripture - the Book of Revelation}

This brings us to the provisional end of our reflections: God becomes manifest in a scripture that embodies those moments in our lives when we are touched

38 Also E. Jüngel, God as the mystery of the world. On the theology of the Crucified in the Controversy of Theism and Atheism, London: Bloomsbury 2014, 215 seems to go in this direction when he speaks of the fact that a "Christian eschatology would thus think of eternal life as the revelation of life is lived with all of the possibilities which surround it, that is, not merely as the eternalizing of the possibility out of which our life became possible, but rather as the revelation and implementation of all those possibilities into which our life constantly moves without ever having realized them.".

39 On this aspect, see M. Neri, Il corpo di Dio. Dire Gesù nella cultura contemporanea (EDB 85), Bologna 2010. 
by contingency. This scripture takes the form both of a universal canon of narratives of tangibility as "sublated history" and the infinite variety of particular and personal forms of perpetuation. Today, it seems, people have lost the sense of the ideational body that this denotes in which our injuries, celebrations, and stories are inscribed (no one would dare to suggest that, in the deepest sense, this may in fact be the most genuine form of the church; words such as "body of Christ", incarnation, and so on threaten to degenerate into farce) and therefore these inscriptions are made in a different way, for example in the omnipresent tattoos. It seems to me that these express an infinite longing for real experience of one's own individuality, in other words for a moving encounter with the other, though the other is barely able to penetrate the thick layer of our virtualities.

I would now like to steer the ideas presented above in a philosophy-of-history direction by looking at the final text (scar, engraving) of the Bible, the Book of Revelation.

1. Through its last book the Bible is given a framework that is both spatially and temporally universal. Spatially, the Book of Revelation extends, starting with the island of Patmos and the seven churches of Asia Minor, over the entire globe and beyond to heaven and hell, to the sphere of the dead, the surviving, and the heavenly court. Temporally, this scripture, which completes the canon, extends the Bible to all of history, from its beginnings or even from the period before its beginnings (as in the first chapters of Genesis) to its end and even beyond. Christians' holy scripture is thus the transformation of all of history into text or, in light of the ideas presented here, the insertion of history into that second body of total tangibility and exposure in which the scars of creaturely existence are engraved.

It might help us to reflect on the relationship of this text to "chronological" history if we turn to the closing reflections in Hegel's Phenomology. Also Hegel's text indirectly structures human, or at least European history, in accordance with certain figures of knowledge. According to Hegel, time is the sublation of mere now-moments; it is not simply a physical phenomenon. Time is the expression of spiritual conscious-being (Bewusst-Sein), in other words of a world that cannot be regarded merely as an object but is located at the point of transition between subject and object or immanence and transcendence. In the transitionality of these forms of conscious-being time in turn takes shape in certain epistemic and religious figures, or we might also say in specific eras, in which a particular form of conscious-being predominates.

The focus of these eras are the transitions that take place, which is why they never represent a sequence that might be apprehended in a positivist sense. The decisive transition was the one between the absolute and the contingent, 
which the community saw in Jesus Christ, towards whom "chronological" history retrieves without exhausting itself.

The associated perception of this transition as the tree of life in its total tangibility, vulnerability and exposure - when the self begins to relocate itself, relinquishing its shields, masks and projections - thus offers a kind of texture or second skin or second body or, in patristic terms, "clothes of grace" for the human being. This finds paradigmatic expression in the structure of the Bible as an embodiment of this "tree of life." If we look at its relationship to the Phenomenology, the tree of life represents both its end point as well as its reference point.

2. A second important consideration is the position of the Book of Revelation within the canon, which it completes. In point one above I drew attention to the way this scripture embeds the canon in a universal temporal framework in which the entire cosmos (in a Hegelian sense) is sublated. In addition, Revelation also is distinguished by the fact that it recapitulates the entire canon. It provides a kind of textual collage of every part of the preceding scriptures, which are never quoted verbatim, but now are re-read at the end of the entire story (or must be). The canon is translated or, in fact, revoked into images and this translation creates a collage-like historical retrospective featuring multifarious ruptures that extend all the way into grammar. ${ }^{40}$

We thus find in this work elaborate rhetorical figures alongside - from a superficial standpoint - the most simple grammatical errors. ${ }^{41}$ So one of the book's messages is that God can no longer be detected linguistically or grammatically, or that we can only get a sense of God through a ruptured language and displaced images. My colleague Jacob Deibl drew my attention to the fact that the Christian's canon begins with stories, but concludes in the form of letters. The Book of Revelation, addressed both to the seven churches and their angels and to Jesus Christ (!) (Rev. see. 1:5b), is no exception. So the canon ends with a personal, amicable mode of address, which is amplified by a proclamation of seven beatitudes (the number of fullness), the last of which refers back to the tree of life. So the last dimension is the transformation of speech into prayer (see Part IV "The Price of Prayer").

3. The book of Revelation provides not only a great historical arc and recapitulates the Scripture, it also comprises its epilogue, a postscript to history,

40 See also G. Biguzzi, Apocalisse, Milano 2005, esp. 6o. See also T. Paulsen, On the Language and Style of the Apocalypse of John (manuscript not yet published, kindly provided by T. Nicklas).

41 See G. Biguzzi, Apocalisse, Milan 2005, esp. 6o. 
already evident in its transmission on the eighth day, Sunday, the Lord's day (Rev. 1:10). For this purpose it is in its main parts retrospective, which also includes the future. In this context it should be taken into account that from a Christian perspective, our existence represents such an epilogue. It is (in sacramental terms) not life, but death that Christians leave behind: their life thus represents a transition between life and death as do the lives of all human beings, then a transition between death and life in baptism, eventually becoming a transition between death and death and thus a radical splitting of this enigmatic event. Christian time is threshold time, and in the literal sense completed, that means it is "full-ended" (voll-endet) (located between two ends).

The structure of the Book of Revelation conveys the significance of this epilogue. The great arch extends from the letter to the seven churches, the seven seals, seven trumpets and seven bowls, and finally back to seven visions in which the suffering and violence of human history is described retrospectively in a staccato of images. Once this history of violence has come to an end to the point where previous sites of action (heaven, earth) have vanished entirely, a vision is invoked that first involves a description of the new, hospitable Jerusalem, before passing over in a voice that blesses those who participate in the tree of life, those who are affected by the stories of suffering in the world (a counter-image can be found in Revelation 18:7, where Babylon declares that she doesn't know any grief). This auditory account finally disappears in favor of a testimony of the book, into which the tree of life is transformed. This ultimately culminates in a liturgy that includes prayer for the coming of the Lord Jesus and concludes with a blessing for all ("The grace of the Lord Jesus be with all!").

Thus Revelation, construed as epilogue to the Scripture, successively dismisses all images in which it had recalled and reconfigured the entirety of history, including the final utopian vision, before transitioning into a blessing that signifies the peroration of time, the tree of life, the Book and the second skin / the second body as manifestation of the kyrios.

\section{B. Moonbeams by Sunlight}

The epilogue of history recapitulates this history in order to dismiss it, that is, the dominance of certain forms, and thus allows it to relate freely to the individual forms, without having to dissociate itself from them in abstract fashion. According to the Revelation, this epilogue opens into a feast, and finally into a blessing. It seems now that the initial question asked can be answered - what is celebrated on the seventh (or eighth) day? It is the transformation of the external event, of the chronological, seemingly meaningless world, of history into a space of encounter where the human being, in affirmation of its contingency, 
becomes nothing but sensitivity, that is, a second body of tangibility at the intersection of the human being and God. In a sense, the festive encounter and the vitality and creativity contained in it, far from being the repression of death and the oblivion of contingency - that would be their farce - turns out to be the most profound expression of that corpus.

In an exceptionally profound way, one of the great works of world literature, namely Robert Musil's The Man Without Qualities ${ }^{42}$ bears witness to this. Its chronological framework already gives us something to think about. The whole work takes place immediately before the outbreak of World War I, before Europe's great apocalypse. This framework has an asymmetrical parallel in the age of the protagonist, Ulrich, who is $3^{2}$ years old, right at the threshold of the age of Christ when he (at least according to tradition) was crucified. At the same time, however, the work points beyond the Apocalypse, which unfolds - true to Austrian style - as a farce.

The plot is centered around the so-called "Parallel Campaign", which is to "bring to bear the full weight of a seventy- year reign, so rich in blessings and sorrows, against the jubilee of a mere thirty years". ${ }^{43}$ This is a reference to the government anniversaries of the two emperors Franz Joseph I of Austria and Wilhelm II of Germany. We know that this anniversary of Franz Joseph never took place, because he had already died in 1916 (that is, after 68 years of reign). In this sense, the parallel action is something doubly absurd because first it will be the anniversary of a dead person, and second because it also coincides with the fall of the Austrian Empire.

Despite its impending collapse, the Parallel Campaign is centered around a motto which expresses Austria's status as the "true location of the world spirit". 44 Ultimately, the Parallel Campaign turns out to be an immense series of meetings, intrigues, discussions, and full participation polls that are only missing one thing - content or, if you will, a global idea that could cover everything. In this sense, the main protagonist, Ulrich, is the ideal secretary for this activity because he is a "man without qualities", a person with no guiding idea, who has lost the "elementary, narrative mode of thought to which private life still clings, even though everything in public life has already ceased to be narrative and no longer follows a thread, but instead spreads out as an infinitely interwoven surface". 45

42 Quotations in what follows from The Man Without Qualities, vols 1 and 2, translated by Sophie Wilkins, New York 1996.

43 Musil, The Man Without Qualities, 87.

44 Musil, 185 (translation modified).

45 Ibid., 709 . 
Taking an overall view of this profoundly Austrian work, one can say that it has an apocalyptic dimension (if we take the word "apocalyptic" to imply doomsday, not a new beginning): it plays out towards the end of the old Austria, but far beyond this it deals with a world in which the Messiah does not come to full age. It takes place in a world that exceeds its own demise as farce (as indicated by the seventy-year anniversary for Emperor Franz Joseph I that never took place). It is a world that seems to know, above all, no hope for the future. When one gives an inaugural lecture at the University of Vienna in a humanities context, the (post-)apocalyptic nexus of the city should be mentioned.

Vienna is not only the city, which is the source of key global intellectual achievements of the 2oth century - one should only think of Freud's psychoanalysis, twelve-tone music of Schönberg, Gödel's incompleteness theorem, Schrödinger's quantum physics, the philosophy of language by Wittgenstein and the art of Schiele and Klimt - but also the city with a pronounced apocalyptic literature - that of Musil, Kraus, Horváth and later Bernhard or Bachmann. This is shaped by the fact that it has lost faith in the validity of the old world without being able to confront the world with a new utopian project. It is a world of the vanishing present and the lost future. As such, it is a world that goes far beyond "Austria" and is now affecting more and more regions of world culture. One might say that this is a world that has history behind it, so in a sense, a post-mortem world.

What can appear theologically particularly fascinating in this novel by Musil is the fact that this "post mortem", which, as we have seen, is central to a Christian understanding of time, is discussed in its religious dimensions. In Christian terms we can say that this "post mortem" time can be understood as the time between baptism, where the old man dies, and in which there is a transition from the world of the living dead to life, and the parousia of Christ. It is thus a time that indicates a transition between death and death, in which death no longer means the enigmatic and nullifying nothingness, but a radical relocationary step out of one's own projections and thus into a new capacity to be touched by and absorb life.

Furthermore, it should be stressed that in this "between" of death and death this death itself is splitted. Christians have death, and the goal of history, namely the resurrection of Christ as messianic event, ahead of and behind them and thus find themselves at the thresholds of times and of life, that is on the threshold of the future and the past.

These thresholds constantly merge into one another and thus do not express any unilateral passage of time with an increasing accumulation of pasts. The Christian path thus leads not only from the past to the future, but also from the future into the past. The world in which we live is both a "past" and 
a "future" world or a world of the "between" of future and past. Our "arrival" in the present takes place in this way "too late" or "too early", but in any case "a-present". The futur antérieur that this implies and the a-presence of Christian existence means that Christian existence signifies an arrival ("after the fact", post festum) in that which is already prepared, in order to (in view of the parousia) take leave of it. Seen in this light Christianity is neither a utopian project geared towards a future yet to come, nor a retrospective project, which remains rooted in the past. It is also not self-fixing in the various abodes and images of a firmly grasped present. Rather it crosses the times and is deeply anachronistic. Musil's protagonist Ulrich gets to the heart of the matter: "God is profoundly un-modern: we simply cannot imagine him in tails, clean-shaven, with neatly parted hair; our image of him is still patriarchal". 46

Musil could be seen as the supreme guide for anyone wanting to explore the terrain of this anachronism. His work features a transition from an apocalypticin the conventional sense, i.e. a hopeless scenario of dissolution - towards an "anachronistic search for God".

The first part of The Man Without Qualities provides a lucid portrayal of this dissolution of all ideas and hopeful scenarios. The grand projects and narratives are exhausted and no longer credible. The world, following the "principle of insufficient cause" 47 , lacks a guiding idea and - just like the man without qualities, who is unequal to the epic task of producing a coherent narrative disintegrates into a multiplicity of moments, into particles of thought and time.

One aspect of this process of disintegration is expressed in the fact that for Ulrich the world increasingly disappears as the mirror surface of his own desire and the site of the realization of his action, prompting him to take "holiday from life". In this scenario, a re-locationary step begins to manifest itself within him, analogous to the transition of spirit and religion in Hegel's Phenomenology. This re-locationary step, for which the ground has already been laid in a man who can no longer locate his "self" in the world, who is "qualities without a man"48, finds its embodiment in the re-encounter of the protagonist with his sister Agathe, from whom Ulrich was separated in early childhood. The two worlds that can be found in Ulrich (but also in Agathe), namely the world of rationalcritical insights and the affective world of a so-called "faith", which is nothing less than a condition of not-knowing or a doubling of knowledge, enter into a fruitful tension through Ulrich's relationship with Agathe who, like Ulrich, is also a critical spirit, but who also possesses high emotional intelligence.

$\begin{array}{ll}46 & \text { Ibid., 211. } \\ 47 & \text { Ibid., 139. } \\ 48 & \text { Ibid., 156. }\end{array}$


In a perilous and passionate love that risks crossing the borderline into physical love (incest), both enter the "thousand-year empire", "where life grows in a magical silence like a flower"49 and whose transitions bring heaven and earth to meet. Ulrich and Agathe are in a "garden" of "day-bright mysticism" of contingent and sensuous realms whose certainty - as in Hegel's turn back from absolute knowledge to sensuous certainty - they experience in a new way because the old images and self-reflections have been shattered. Invisible and yet uniquely real "moonbeams by sunlight" 50 shine down into this day-bright mysticism of everyday perception of the world.

They represent a kind of "splendor" of the Absolute and refer to that "second skin" of pure tangibility and vulnerability at the sight of which the world can arise, at least momentarily, in a new festive way. And in the permanent loss and the painful devaluation of all images and conceptions of the world, that is in the contingency and transience of temporal forms that provide no final foothold, all at once the "face of time" becomes "deceptively beautiful, and radiant, by a single thought! For what if it were God Himself who was devaluing the world? Would it not then again suddenly acquire meaning and desire? And would $\mathrm{He}$ not be forced to devalue it, if He were to come closer to it by the tiniest step? And would not perceiving even the anticipatory shadow of this already be the one real adventure?!"51

Perhaps this is Christianity's contribution to a new humanism in our time. Now that the great utopias have faded away and the world faces unprecedented threats, veiled by an impenetrable mirror of media-based and intellectual selfreflection that refers to "nothing", a Christian perspective can help us break away from the media-generated and abstract images (to "devalue" them). It can help us move on from the large but now empty words produced by theology and the churches (along with politics and the academy), which dangle before us too much love and alterity and salvation but not enough contingency and gestures of mercy. This shift is linked to the adoption of a culture of tangibility and a perception of the vulnerability of being (what would be the churches' present-day purpose if not this: to function as the network or structure of such tangibility, to be a universal "second skin"), whose (visible and ideational) body is celebrated on the seventh day as the epilogue to creation, in a feast given by HIM.

I will close with a quote from Musil, "human activities might be graded by the quantity of words required: the more words, the worse their character." 52

\footnotetext{
49 Musil, The Man Without Qualities II, 1118.

5O Musil, II 1182.

51 Ibid., II, 1189.

52 Musil, The Man Without Qualities, 264.
} 